九州大学学術情報リポジトリ

Kyushu University Institutional Repository

Expression of mRNA in the frontal cortex and hypothalamus in a rat model of acute carbon dioxide poisoning

佐藤，和雄

https://doi.org/10.15017/1654800

出版情報：九州大学，2015，博士（歯学），課程博士 バージョン:

権利関係：全文ファイル公表済 


\title{
Expression of mRNA in the frontal cortex and hypothalamus in a rat model of acute carbon dioxide poisoning
}

\author{
Kazuo Sato $^{\mathrm{a}, \mathrm{b}}$, Akiko Tsuji $^{\mathrm{a}}$, Yosuke Usumoto ${ }^{\mathrm{a}}$, Keiko Kudo ${ }^{\mathrm{a}}$, Takeshi Yokoyama ${ }^{\mathrm{b}}$, Noriaki Ikeda ${ }^{\mathrm{a}, *}$ \\ a Department of Forensic Pathology and Sciences, Graduate School of Medical Sciences, Kyushu University, Fukuoka 812-8582, Japan \\ ${ }^{\mathrm{b}}$ Department of Dental Anesthesiology, Faculty of Dental Science, Kyushu University, Fukuoka 812-8582, Japan
}

\section{A R T I C L E I N F O}

\section{Article history:}

Received 30 June 2015

Received in revised form 24 July 2015

Accepted 25 July 2015

Available online 26 July 2015

\section{Keywords:}

Carbon dioxide poisoning

Pathophysiology

mRNA

The frontal cortex

The hypothalamus

\begin{abstract}
A B S T R A C T
Acute carbon dioxide $\left(\mathrm{CO}_{2}\right)$ poisoning causes no specific features that are revealed upon autopsy, and the pathophysiological mechanism of this syndrome is unclear. To address this issue, in the present study, we exposed rats to $\mathrm{CO}_{2}$ concentrations ranging from $10 \%$ to $60 \%$ and determined the effects on mRNA expression. According to the results of Gene Ontology (GO) and cluster analyses of microarrays data, we selected the following genes for further analysis: alkylglycerone phosphate synthase (Agps), hypocretin (Hcrt), tyrosine hydroxylase $(\mathrm{Th})$, heat shock protein beta $2(\mathrm{Hspb2})$, and opioid receptor delta 1 (Oprd1) expressed in the frontal cortex and renin (Ren), pancreatic polypeptide (Ppy), corticotropin releasing hormone receptor 2 (Crhr2), carbonic anhydrase 1 (Car1), and hypocretin receptor 1 (Hcrtr1) expressed in the hypothalamus. We found significant differences between the expression levels of Agps and Hspb2 mRNAs in the frontal cortex and that of Ppy, Crhr2 mRNAs in the hypothalamus in the presence of high concentrations of $\mathrm{CO}_{2}$. Further investigation of these genes may clarify the pathophysiology of acute $\mathrm{CO}_{2}$ poisoning and facilitate the development of novel forensic tests that can diagnose the cause of death.
\end{abstract}

(c) 2015 Elsevier Ireland Ltd. All rights reserved.

\section{Introduction}

Carbon dioxide $\left(\mathrm{CO}_{2}\right)$ is a colorless and odorless gas that represents $0.03 \%$ of the constituents of air. $\mathrm{CO}_{2}$ poisoning causes headache, dizziness, nausea, tremor, and fainting [1-3]. In forensic casework, we encounter deaths caused by acute $\mathrm{CO}_{2}$ poisoning from exposure to gaseous or solid (dry ice) $\mathrm{CO}_{2}$. However, because acute $\mathrm{CO}_{2}$ poisoning does not exhibit specific characteristics upon autopsy, except for the congestion of organs [4,5], the cause of death is sometimes mistakenly attributed to hypoxia induced by suffocation.

The details of the mechanism and pathophysiology of $\mathrm{CO}_{2}$ poisoning are not understood in detail. We do know that exposing rats to $\mathrm{CO}_{2}$ gas in the absence of oxygen $\left(\mathrm{O}_{2}\right)$ rapidly induces acidosis

Abbreviations: Agps, alkylglycerone phosphate synthase; Car1, carbonic anhydrase 1; $\mathrm{CRH}$, corticotropin releasing hormone; Crhr2, corticotropin releasing hormone receptor 2; FDR, False Discovery Rate; GO, Gene Ontology; Hspb2, heat shock protein beta 2; Hcrt, hypocretin; Hcrtr1, hypocretin receptor 1; NPY, neuropeptide Y; Oprd1, opioid receptor delta 1; Ppy, pancreatic polypeptide; Ren, renin; SAM, significant analysis of microarrays; Th, tyrosine hydroxylase.

* Corresponding author at: Department of Forensic Pathology and Sciences, Graduate School of Medical Sciences, Kyushu University, 3-1-1 Maidashi, Higashiku, Fukuoka 812-8582, Japan.

E-mail address: n-ikeda@forensic.med.kyushu-u.ac.jp (N. Ikeda). and terminates breathing, suggesting that respiratory acidosis causes the ensuing fatal arrhythmia [6]. In contrast, $\mathrm{CO}_{2}$ poisoning is induced in dogs exposed to $20 \% \mathrm{O}_{2}$ and $80 \% \mathrm{CO}_{2}$ gas, which suppresses respiration and circulation by inhibiting the activity of the central nervous system and by enhancing the effects of parasympathetic nerve activity [7].

To better understand the pathophysiology of $\mathrm{CO}_{2}$ poisoning, we developed a rat model of acute $\mathrm{CO}_{2}$ poisoning by exposing rats to a range of $\mathrm{CO}_{2}$ gas concentration (10-60\%). We then analyzed the levels of gene expression in the frontal cortex and hypothalamus.

\section{Materials and methods}

\subsection{Rat model of acute $\mathrm{CO}_{2}$ poisoning}

The Animal Care and Use Committee of Kyushu University approved the experiments using rats (Nos. A24-225-0, A26-003-0). Wistar rats (eight males, 8-weeks-old, body weight range 301-360 g) (Kyudo Co., Ltd., Saga, Japan) were anesthetized using intraperitoneal injection of medetomidine $(0.15 \mathrm{mg} / \mathrm{kg})$ (Domitol, Kyoritsu Seiyaku Co., Ltd., Tokyo, Japan), midazolam ( $2 \mathrm{mg} / \mathrm{kg}$ ) (Dormicum, Sandoz Co., Ltd., Tokyo, Japan), and butorphanol $(2.5 \mathrm{mg} / \mathrm{kg})$ (Vetorphale, Meiji Seika Pharma Co., Ltd., 
Tokyo, Japan). After confirming anesthesia, the rats were placed in a restrainer, and four were exposed to $40 \% \mathrm{CO}_{2}\left(\mathrm{O}_{2}, 20 \% ; \mathrm{N}_{2}, 40 \%\right)$ for $15 \mathrm{~min}$ using a nose-only inhalation apparatus (Shin Factory, Fukuoka, Japan) (experimental group). The four rats in the control group were allowed to breathe air normally for $15 \mathrm{~min}$. Cervical dislocation was used to sacrifice all rats. The $\mathrm{CO}_{2}$ concentration and exposure time were chosen according to published results to allow the expression of detectable levels of mRNAs [1,7].

\subsection{Selection of picking region}

We selected the frontal cortex because it mediates recognition and judgment, and because the symptoms of mental disorders are exhibited by patients with acute $\mathrm{CO}_{2}$ poisoning [1,2]. The hypothalamus was selected, because it controls the medulla of vital autonomic nerves that are required for circulation, respiratory movement, and homeostasis.

\subsection{RNA isolation and reverse transcription}

The frontal cortex and hypothalamus were immediately dissected after cervical dislocation. Tissues were homogenized using a Bio Mashe (Nippi Co., Ltd., Tokyo, Japan) according to the manufacturer's instructions, and total RNA was extracted using a Maxwel 16 System (Promega Corporation, Madison, WI, USA) and a Maxwell 16 LEV simply RNA Tissue Kit (Promega Corporation). Total RNA (1000 ng) was utilized as a template, and complementary DNA (cDNA) was synthesized using a Veriti 96-Well Thermal Cycler (Applied Biosystems, Foster City, CA, USA) and a High Capacity RNA-to-cDNA kit (Applied Biosystems).

\subsection{Microarray and data analysis}

The cDNAs transcribed from the frontal cortex and hypothalamus RNAs were hybridized with 44,256 probes included in the oligo DNA tip (Agilent Technologies, Santa Clara, CA, USA). After eliminating control probes, overlapping probes and probes that detect significant decreases in expression levels, 24,305 and 25,089 were extracted from the frontal cortex and hypothalamus, respectively. After the probe signals were normalized to the median expression levels of all probes included in the microarray, probes with signals that differed greater than twofold in intensity than those of control group were analyzed. We used the significance analysis of microarrays $t$ statistic method for microarray statistical analysis [8].

We then selected probes with $t$-test $p$ values $<0.05$ and performed Gene Ontology (GO) analysis of 1460 and 992 probes selected from the frontal cortex and hypothalamus, respectively, with levels of expression that were lower than 2-fold. Further, of 24,305 and 25,089 probes of the frontal cortex and hypothalamus, respectively, 23,455 common were merged, and ANOVA was performed to compare the data of each of the four experimental and control groups prepared from each tissue. After the $p$ value calculated using ANOVA was converted to the False Discovery Rate (FDR), we performed eight divided cluster analyses of 14,248 probes with FDR values $<0.05$.

\subsection{Effects of $\mathrm{CO}_{2}$ concentration on mRNA levels}

Of 50 male Wistar rats (8-weeks-old, $301-360 \mathrm{~g}$ body weight) (Kyudo Co., Ltd.), 10 were allowed to breathe air (control group), and groups of 10 each of the remainder were exposed to $10 \%$, $20 \%, 40 \%$, and $60 \% \mathrm{CO}_{2}$ gas, respectively. For each $\mathrm{CO}_{2}$ concentration, the $\mathrm{O}_{2}$ concentration was maintained at $20 \%$ and the $\mathrm{N}_{2}$ concentration was adjusted according to the $\mathrm{CO}_{2}$ concentration. After exposure, cervical dislocation was used to sacrifice the rats. Total
RNA was isolated, and cDNA was synthesized as described in Section 2.2. The cDNAs were stored at $-20^{\circ} \mathrm{C}$.

\subsection{Quantitative real-time polymerase chain reaction analysis}

Quantitative real-time polymerase chain reaction (PCR) was performed in a $20-\mu \mathrm{l}$ reaction mix using the TaqMan Gene Expression Assays (Applied Biosystems) and TaqMan Fast Advanced Master Mix (Applied Biosystems) with a StepOne Real Time PCR System (Applied Biosystems). The contents of the amplification mix and thermal cycling conditions were set according to the manufacturer's instructions. The primers for alkylglycerone phosphate synthase (Agps), hypocretin (Hcrt), tyrosine hydroxylase (Th), heat shock protein beta 2 (Hspb2), opioid receptor delta 1 (Oprd1), renin (Ren), pancreatic polypeptide (Ppy), corticotropin releasing hormone receptor 2 (Crhr2), carbonic anhydrase 1 (Car1), and hypocretin receptor 1 (Hcrtr1) were purchased from Applied Biosystems. The expression levels of the target transcripts are presented as the ratio of the targets normalized to those of the reference $\beta$-actin (Actb) mRNA.

\subsection{Analysis of $m R N A s$ expressed in the brain}

The expression levels of each mRNA were determined using the $\Delta \Delta \mathrm{Ct}$ method. All statistical analyses were performed for the $\Delta \mathrm{Ct}$ data to exclude potential bias due to the averaging of data calculated using the equation $2^{-\Delta \Delta \mathrm{Ct}}$. To compare data between groups, the nonparametric test Steel-Dwass test was performed using JMP11 software (SAS, Cary, NC, USA). A $p$ value $<0.01$ was considered statistically significant.

\section{Results}

\subsection{Selection of candidate genes}

Table 1 shows the number of probes with signals that varied in intensity by more than twice the value of variation compared with those of the control group with SAM $t$-test values $<0.05$. The numbers of genes downregulated twofold were greater than those of the genes upregulated twofold. GO analysis of the downregulated probes representing both tissues revealed that the most frequently represented gene clusters with low $p$ values were as follows: (1) genes encoding components of $G$ protein-coupled receptor pathways, (2) genes encoding proteins involved in olfaction, and (3) genes encoding proteins involved in transcription (Table 2).

Among the probes detected in each tissue, genes encoding proteins that mediate homeostasis and nerve function are involved in components of $\mathrm{G}$ protein-coupled receptor pathways. Further, cluster analysis of 24,305 and 25,089 probes representing the frontal cortex and hypothalamus, respectively, revealed significant differences between the experimental and control groups in clusters 5 and 6 (Fig. 1). Cluster 5 included the same genes related to homeostasis and the nervous system that encode components of $G$ protein-coupled receptor pathways. According to these results, we selected the target genes as follows: frontal cortex - Agps, Hcrt, Th, Hspb2, and Oprd1; hypothalamus - Ren, Ppy, Crhr2, Car1, and Hcrtr1 (Table 3).

\section{Table 1}

Computation of gene expression levels.

\begin{tabular}{lll}
\hline & Frontal cortex & Hypothalamus \\
\hline 2 up-regulation and SAM $(t$-test $)<0.05$ & $146 / 24,305$ & $211 / 25,089$ \\
2 down-regulation and SAM $(t$-test $)<0.05$ & $1460 / 24,305$ & $922 / 25,089$ \\
\hline
\end{tabular}


Table 2

The results of GO (Gene Ontology) analysis.

\begin{tabular}{lll}
\hline GO term & Frontal cortex & Hypothalamus \\
\hline G-protein coupled receptor signaling pathway & 89 & 57 \\
Detection of chemical stimulus involved in sensory perception of smell & 73 & 46 \\
Positive regulation of transcription, DNA-dependent & 30 & 21 \\
\hline
\end{tabular}

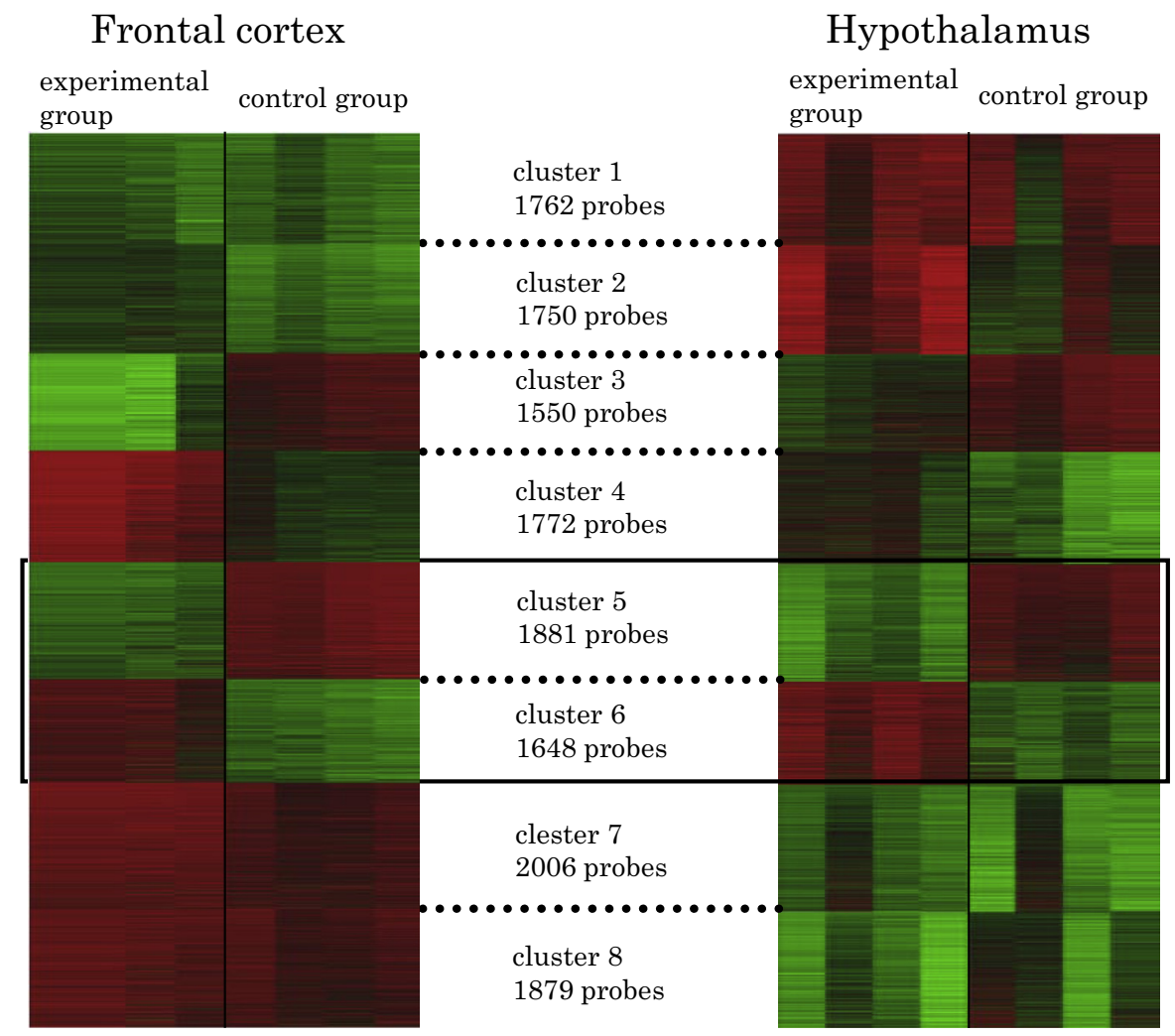

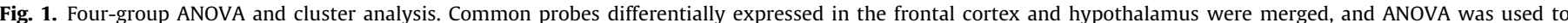

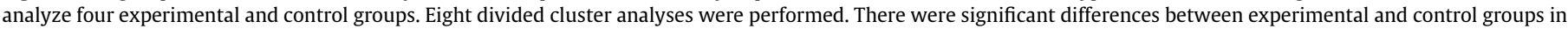
clusters 5 and 6 that are enclosed with black lines (red, high expression and green, low expression).

\subsection{Effects of $\mathrm{CO}_{2}$ exposure}

Increased respiration was observed for all anesthetized rats when they were exposed to $\mathrm{CO}_{2}$ gas. Rats survived when they were exposed to $\mathrm{CO}_{2}$ concentrations ranging from $10 \%$ to $40 \%$. In contrast, four out of 10 rats died within 10-15 min when exposed to $60 \% \mathrm{CO}_{2}$. Death was confirmed by observation of respiratory arrest, cloudy eyes, and absence of a hematoma after cervical dislocation (vital reaction).

\subsection{Expression of $m R N A s$ in the frontal cortex}

Fig. 2 shows the comparative levels $(\Delta \mathrm{Ct})$ of expression of five candidate genes differentially expressed in the frontal cortex of rats exposed to $10-60 \% \mathrm{CO}_{2}$. There were significant differences in the levels of Agps and Hspb2 mRNAs between the control, $10 \%$, $20 \%$, and $40 \% \mathrm{CO}_{2}$ groups and the $60 \% \mathrm{CO}_{2}$ group (Fig. $2 \mathrm{a}$ and b). The levels of Th, Oprd1, and Hcrt mRNAs were not significantly different between any experimental and control groups (Fig. 2c-e).

\subsection{Expression of mRNAs in the hypothalamus}

Fig. 3 shows the comparative levels ( $\Delta \mathrm{Ct}$ ) of expression of five candidate genes differentially expressed in the hypothalamus of rats exposed to $10-60 \% \mathrm{CO}_{2}$. There were significant differences between the levels of Ppy and Crhr2 mRNAs of the $20 \% \mathrm{CO}_{2}$ and $60 \% \mathrm{CO}_{2}$ groups (Fig. 3a and b). The levels of Car1, Hcrtr1, and Ren mRNAs were not significantly different between any experimental and control groups (Fig. 3c-e).

\section{Discussion}

4.1. Evaluation of genes with significant expression change in the frontal cortex after $\mathrm{CO}_{2}$ exposure

AGPS is expressed in peroxisomes and plays a key role in the biosynthesis of phospholipids [9]. Expression of Agps mRNA is increased in the frontal cortex of patients with Alzheimer disease [10], and high levels of phosphorylated tau protein are present in the frontal cortex of a patient with psychotic Alzheimer disease [11]. In the present study, the expression of Agps mRNA in rats exposed to $60 \% \mathrm{CO}_{2}$ was significantly increased compared with that of the other groups. Acute $\mathrm{CO}_{2}$ poisoning due to high $\mathrm{CO}_{2}$ absorption increased the expression of AGPS in the frontal cortex, which might cause the increased phosphorylation of proteins in the brain, leading to suppression of the regulation of material transportation in brain cells. These mechanisms may lead to a condition similar to that of neurodegenerative diseases, which cause 
Table 3

Selected genes. Of the $G$ protein-coupled receptors and proteins involved in homeostasis and the nervous system, we selected five genes that were each expressed in the frontal cortex and hypothalamus with low $p$ values determined using the SAM $t$-test.

\begin{tabular}{ll}
\hline & SAM $t$-test $p$ value \\
\hline Frontal cortex & \\
Agps (alkylglycerone phosphate synthase) & 0.0001428 \\
Hcrt (hypocretin) & 0.0002325 \\
Th (tyrosine hydroxylase) & 0.001458 \\
Hspb2 (heat shock protein beta 2) & 0.001709 \\
Oprd1 (opioid receptor delta 1) & 0.01445 \\
Hypothalamus & \\
Ren (renin) & 0.0001295 \\
Ppy (pancreatic polypeptide) & 0.0001718 \\
Crhr2 (corticotropin releasing hormone receptor 2) & 0.003883 \\
Car1 (carbonic anhydrase 1) & 0.02841 \\
Hcrtr1 (hypocretin receptor 1) & 0.03850 \\
\hline
\end{tabular}
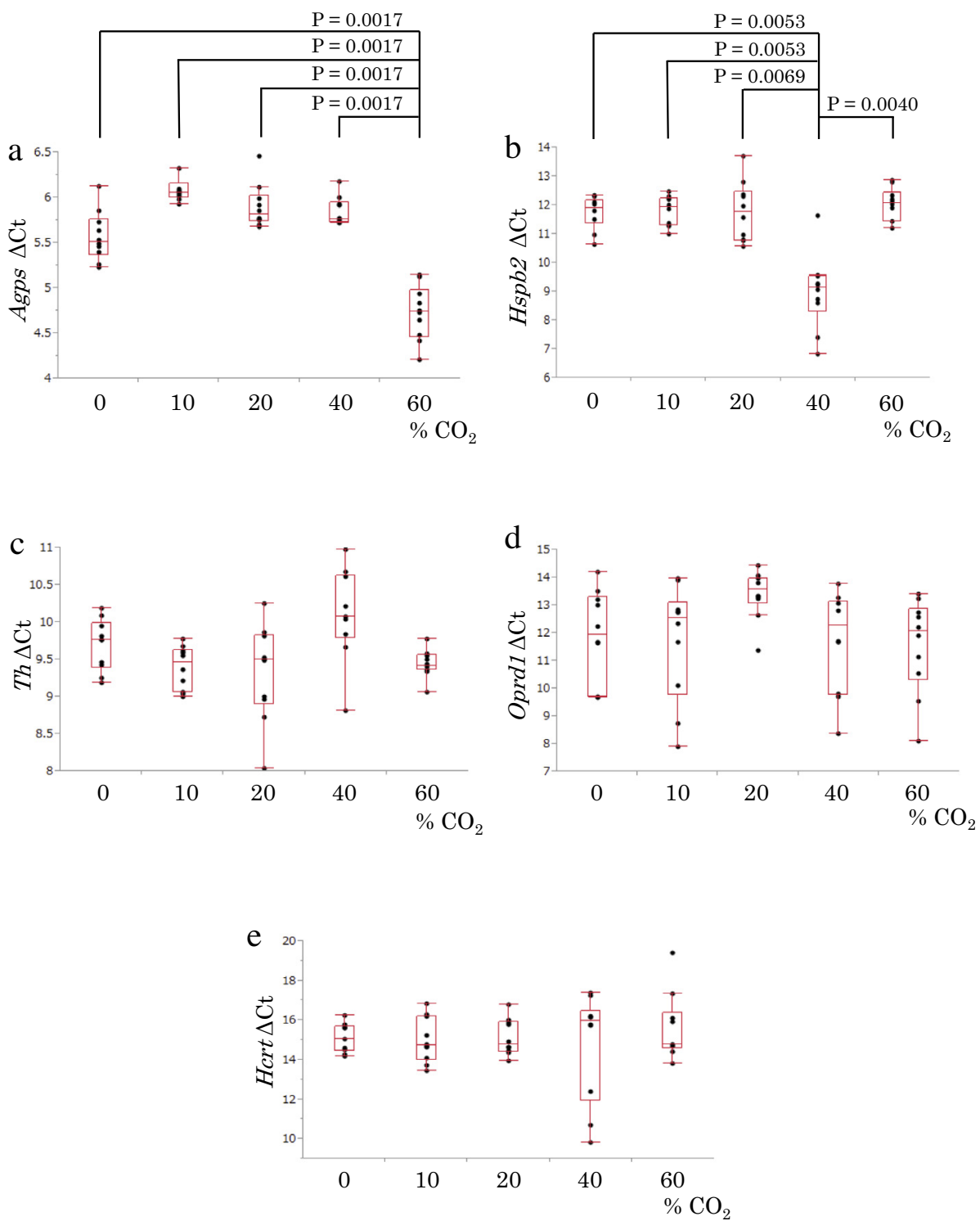

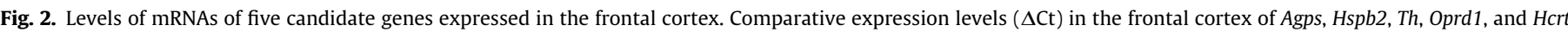

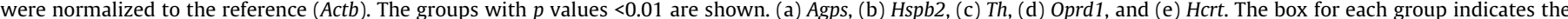

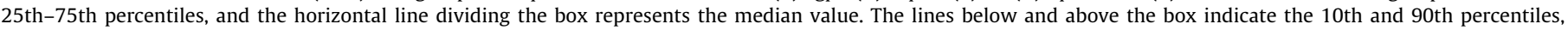
respectively. The points outside the error bars are outliers. 

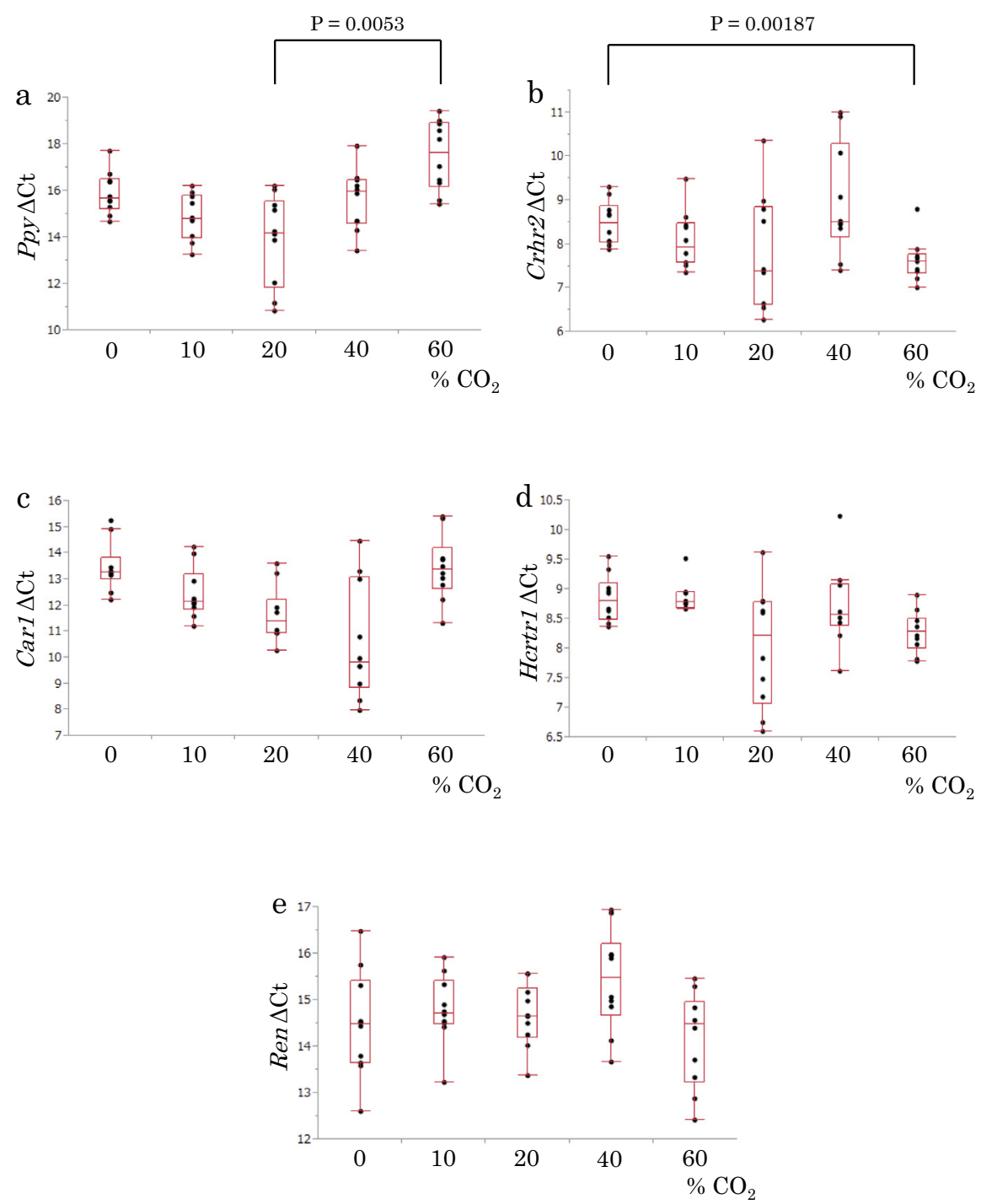

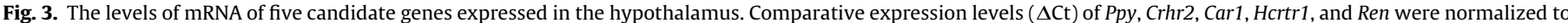

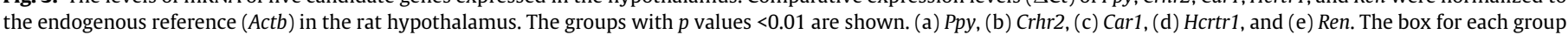

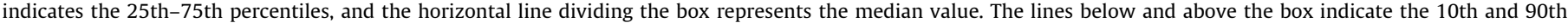
percentiles, respectively. The points outside the error bars are outliers.

\subsection{Analysis of genes with significant change in the hypothalamus after $\mathrm{CO}_{2}$ exposure}

The enzyme PPY, which belongs to the neuropeptide Y (NPY) family, is secreted from PP cells by the islets of Langerhans in the pancreas [16,17]. Npy mRNA levels in the hypothalamus are slightly decreased, whereas the levels of the NPY receptor are significantly decreased when mice are exposed to $5-10 \% \mathrm{CO}_{2}$ for $3 \mathrm{~h}$ [18]. Moreover, activation of NPY signaling pathways may lead to the suppression of respiration [19]. Other studies using rats found that breathing rate is decreased by exposure to $40 \% \mathrm{CO}_{2}$ but increases in the presence of $50 \% \mathrm{CO}_{2}$ [20]. In our present experiments, the expression of Ppy mRNA tended to increase from 0\% to $20 \%$ and decreased in the present of $40 \%$ and $60 \% \mathrm{CO}_{2}$. There was a significant decrease in the level of Ppy mRNA in the 60\% $\mathrm{CO}_{2}$ group compared with those of the $10 \%$ and $20 \% \mathrm{CO}_{2}$ groups. The variation of Ppy mRNA levels may be involved in the suppression of respiration mediated by the hypothalamus in acute $\mathrm{CO}_{2}$ poisoning.

CRHR2 is the receptor for corticotropin releasing hormone and urocortins II and III. It mediates the secretion of the corticotropin releasing hormone ( $\mathrm{CRH}$ ) and is responsible for the modulation for the stress response through CRH [21,22]. In our present experiments, Crhr2 mRNA levels were significantly increased by exposure of rats to $60 \% \mathrm{CO}_{2}$ compared with that in the control group. Therefore, CRHR2 may be involved in the control of stress induced by high $\mathrm{CO}_{2}$ absorption.

\subsection{The pathophysiology of acute $\mathrm{CO}_{2}$ poisoning}

In our present experiments, four out of 10 rats died within 1015 min when exposed to $60 \% \mathrm{CO}_{2}$, and the variations in the expression of specific genes in the frontal cortex and hypothalamus were significant in rats exposed to $40 \%$ and $60 \%$. These findings suggest that acute poisoning caused by $40-60 \% \mathrm{CO}_{2}$ may represent a serious condition even in the presence of sufficient concentrations of $\mathrm{O}_{2}$.

The symptoms of acute $\mathrm{CO}_{2}$ poisoning due to high $\mathrm{CO}_{2}$ absorption may be mediated by the increase in the levels of AGPS and HSPB2 in the frontal cortex, leading to dysfunctional intellectual activity such as in patients with Alzheimer disease. In contrast, variations of PPY levels in the hypothalamus may be involved in 
the control of respiration. The increase of Ppy mRNA may be involved in the increase of respiration during the initial stage of acute $\mathrm{CO}_{2}$ poisoning, and the decrease of Ppy mRNA may lead to the suppression of respiration during the terminal stage, finally leading to respiratory arrest. In addition to the change in the level of PPY, the increase in Crhr2 mRNA levels may lead to uncontrollable serious stress induced by acute $\mathrm{CO}_{2}$ poisoning, leading to death.

In summary, we described here the development of a rat model of acute $\mathrm{CO}_{2}$ poisoning that revealed significant differences in the levels of Agps and Hspb2 mRNAs in the frontal cortex and Ppy and Crhr2 mRNAs in the hypothalamus. These findings suggest that AGPS, HSPB2, PPY, and CRHR2 may be involved in the dysfunctional cognition and regulation of the suppression of respiration that are caused by acute $\mathrm{CO}_{2}$ poisoning. We expect that further research on the function of these proteins will define the pathophysiology of acute $\mathrm{CO}_{2}$ poisoning. Moreover, assays for these mRNAs may help identify acute $\mathrm{CO}_{2}$ poisoning as a cause of death.

\section{Conflict of interest}

All authors declare that they have no conflicts of interest.

\section{Acknowledgment}

The authors would like to thank Enago (www.enago.jp) for English language review.

\section{References}

[1] P. Halpern, Y. Raskin, P. Sorkine, A. Oganezov, Exposure to extremely high concentrations of carbon dioxide: a clinical description of a mass casualty incident, Ann. Emerg. Med. 43 (2004) 196-199.

[2] A. Guais, G. Brand, L. Jacquot, M. Karrer, S. Dukan, G. Grévillot, et al., Toxicity of carbon dioxide: a review, Chem. Res. Toxicol. 24 (2011) 2061-2070.

[3] J.L. Scott, D.G. Kraemer, R.J. Keller, Occupational hazards of carbon dioxide exposure, J. Chem. Health Safety 16 (2009) 18-22.

[4] M. Yamazaki, M. Islam, Y. Ogura, K. Honda, H. Tsuchihashi, H. Nishioka, An autopsy case of carbon dioxide intoxication, Nihon Hoigaku Zasshi 51 (1997) 446-451 [in Japanese].

[5] W.R. Rupp, A. Thierauf, H. Nadjem, S. Vogt, Suicide by carbon dioxide, Forensic Sci. Int. 231 (2013) e30-e32.
[6] H. Kuroki, M. Yamazaki, M. Nakamura, H. Inoue, M. Iino, K. Honda, et al., An autopsy case of $\mathrm{CO}_{2}$ (Carbon Dioxide) intoxication and the physiological mechanism, Jpn. J. Forensic Pathol. 7 (2001) 46-53 [in Japanese].

[7] N. Ikeda, H. Takahashi, K. Umetsu, T. Suzuki, The course of respiration and circulation in death by carbon dioxide poisoning, Forensic Sci. Int. 41 (1989) 93-99.

[8] V.G. Tusher, R. Tibshirani, G. Chu, Significance analysis of microarrays applied to the ionizing radiation response, Proc. Natl. Acad. Sci. USA 98 (2001) 51165121.

[9] E.C. de Vet, L. IJlst, W. Oostheim, R.J. Wanders, H. van den Bosch, Alkyldihydroxyacetonephosphate synthase Fate in peroxisome biogenesis disorders and identification of the point mutation underlying a single enzyme deficiency, J. Biol. Chem. 273 (1998) 10296-10301.

[10] M.O. Grimm, J. Kuchenbecker, T.L. Rothhaar, S. Grösgen, B. Hundsdörfer, V.K Burg, et al., Plasmalogen synthesis is regulated via alkyldihydroxyacetonephosphate-synthase by amyloid precursor protein processing and is affected in Alzheimer's disease, J. Neurochem. 116 (2011) 916-925.

11] J. Koppel, C. Acker, P. Davies, O.L. Lopez, H. Jimenez, M. Azose, et al., Psychotic Alzheimer's disease is associated with gender-specific tau phosphorylation abnormalities, Neurobiol. Aging 35 (2014) 2021-2028.

12] S. Prabhu, B. Raman, T. Ramarkrishna, Ch.M. Rao, HspB2/myotonic dystrophy protein kinase binding protein (MKBP) as a novel molecular chaperone: structural and functional aspects, PLoS ONE 7 (2012). e29810.

[13] P. Verschuure, C. Tatard, W.C. Boelens, J.F. Grongnet, J.C. David, Expression of small heat shock proteins HspB2, HspB8, Hsp20 and cvHsp in different tissues of the perinatal developing pig, Eur. J. Cell Biol. 82 (2003) 523-530.

[14] B.B. Kirbach, N. Golenhofen, Differential expression and induction of smal heat shock proteins in rat brain and cultured hippocampal neurons, J. Neurosci. Res. 89 (2011) 162-175.

[15] M.M. Wilhelmus, I. Otte-Höller, P. Wesseling, R.M. de Waal, W.C. Boelens et al., Specific association of small heat shock proteins with the pathological hallmarks of Alzheimer's disease brains, Neuropathol. Appl. Neurobiol. 32 (2006) 119-130.

[16] K. Loh, H. Herzog, Y.C. Shi, Regulation of energy homeostasis by the NPY system, Trends Endocrinol. Metab. 26 (2015) 125-135.

[17] M. Dyzma, K.Z. Boudjeltia, B. Faraut, M. Kerkhofs, Neuropeptide Y and sleep, Sleep Med. Rev. 14 (2010) 161-165.

[18] W. Wang, Q. Li, Y. Pan, D. Zhu, L. Wang, Influence of hypercapnia on the synthesis of neuropeptides and their receptors in murine brain, Respirology 18 (2013) 102-107.

[19] V.Y. Polotsky, M.C. Smaldone, M.T. Scharf, J. Li, C.G. Tankersley, P.L. Smith, et al., Impact of interrupted leptin pathways on ventilatory control, J. Appl. Physiol. 96 (2004) 991-998.

[20] H. Muijser, J.J. van Triel, E. Duistermaat, P.M. Bos, Acute toxicity of high concentrations of carbon dioxide in rats, Regul. Toxicol. Pharmacol. 69 (2014) 201-206.

[21] A. Korosi, J.G. Veening, T. Kozicz, M. Henckens, J. Dederen, L. Groenik, et al. Distribution and expression of CRF receptor 1 and 2 mRNAs in the CRF overexpressing mouse brain, Brain Res. 1072 (2006) 46-54.

[22] Y. Chen, H. Sheng, Y. Xu, Y. Zhang, X. Ni, Activation of CRHR2 exerts an inhibitory effect on the expression of collapsin response mediator protein 3 in hippocampal neurons, Neuropeptides 46 (2012) 93-98. 